\title{
Identifikasi Spesies Fungi Microsporum gypseum dan Microsporum nanum Penyebab Ringworm pada Sapi Bali
}

\author{
(IDENTIFICATION OF FUNGI SPECIES MICROSPORUM GYPSEUM \\ AND MICROSPORUM NANUM THE CAUSATIVE AGENTS \\ OF RINGWORM IN BALI CATTLE)
}

\author{
Putu Ayu Sisyawati Putriningsih, I Putu Gede Yudhi Arjentinia \\ Lab Ilmu Penyakit Dalam Veteriner, Fakultas Kedokteran Hewan, \\ Universitas Udayana, Jl. Sudirman, Denpasar, Bali, Indonesia \\ Telp 0361-223791, E-mail : ay4kato_84@yahoo.com
}

\begin{abstract}
ABSTRAK
Ringworm adalah penyakit kulit infeksius yang dapat menyerang berbagai jenis hewan dan bersifat zoonosis. Penyakit ini disebabkan oleh fungi (cendawan) dermatofita. Kasus ringworm pada sapi cukup banyak dilaporkan di berbagai negara, namun laporan mengenai spesies penyebab ringworm pada sapi bali belum dipublikasikan. Hal ini sangat penting untuk diketahui dalam usaha pemberian terapi yang lebih efektif. Penelitian ini bertujuan untuk mengidentifikasi spesies fungi dermatofita yang menyebabkan ringworm pada sapi bali. Delapan ekor sapi bali yang diduga ringworm diambil sampelnya menggunakan teknik superficial skin scraping dan trichogram (hair pluck). Sampel kerokan kulit dan rambut di daerah lesi diambil untuk dilakukan pemeriksaan mikroskopis langsung terhadap adanya elemen jamur (hifa atau arthrospora). Sampel kerokan kulit dan rambut ditetesi kalium hidroksida (KOH) 10\%, didiamkan selama 10-15 menit, kemudian diamati menggunakan mikroskop cahaya. Sampel kerokan kulit dan rambut yang memperlihatkan hasil positif selanjutnya dikultur pada media Sabauroud's Dextrose Agar (SDA) selama 1-3 minggu dan diidentifikasi menggunakan pewarnaan Lactophenol Cotton Blue dengan bantuan mikroskop cahaya. Data yang diperoleh dianalisis secara deskriptif. Fungi dermatofita yang berhasil diisolasi dan diidentifikasi adalah Microsporum gypseum sebesar 75\% (6/8) dan $M$. nanum sebesar 25\% (2/8). Kedua jamur ini memiliki sifat invasi/infeksi ectothrix yakni pembentukan arthrospora/ arthrokonidia hanya pada bagian permukaan/superfisial batang rambut sehingga terapi topikal sudah cukup untuk mengatasi infeksinya.
\end{abstract}

Kata-kata kunci: Microsporum canis; M. nanum; ringworm; zoonosis; sapi bali

\begin{abstract}
Ringworm is a zoonotic infectious skin disease that can attack various types of animals and human caused by dermatophyte fungi. Ringworm cases in cattle have been widely reported in various countries, however little information regarding the fungal species that caused ringworm in bali cattle. Identification the etiology of ringworm in bali cattle is necessary so that the therapeutic effort is effective. This study aims to identify the species of dermatophyte which caused ringworm in bali cattle. Eight bali cattle suspected of having ringworm were sampled using superficial skin scraping and trichogram (hair pluck) techniques. Skin and hair scrub samples in the lesions area were taken for direct microscopic examination of fungal elements (hyphae or arthrospora). The hair and skin scrapings samples were added 10\% potassium hydroxide $(\mathrm{KOH})$ and allowed to stand for 10-15 minutes prior to microscopic observation. The samples which fungal elements were found then cultured onto Sabauroud's Dextrose Agar (SDA) for 1-3 weeks and further identified using Lactophenol Blue Cotton staining with the help of light microscope. The species of dermatophyte fungi which were successfully isolated and identified were Microsporum gypseum (6/8.75\% ) and $M$. nanum (2/8. 25\%). Both of these fungi has ectothrix type of invasion by forming of arthrospora/ arthroconidia on the surface or superficial of hair shaft, therefore using topical therapy is enough to overcome the infection.
\end{abstract}

Keywords: Microsporum canis; Microsporum nanum; ringworm; zoonotic; bali cattle 


\section{PENDAHULUAN}

Ringworm adalah salah satu penyakit kulit infeksius yang dapat menyerang berbagai jenis hewan. Nama lain penyakit ini yaitu dermatofitosis, karena disebabkan oleh fungi (cendawan) dermatofita. Tiga genus penyebabnya yaitu Microsporum, Trichophyton, dan Epidermophyton (Vermout et al., 2008). Fungi ini dapat menginfeksi lapisan berkeratin seperti stratum korneum kulit, rambut, dan kuku (Bond, 2010).

Sapi merupakan salah satu hewan yang sangat dekat dengan kehidupan masyarakat Indonesia pada umumnya dan masyarakat Bali pada khususnya. Salah satu penyakit yang dapat menyerang sapi termasuk sapi bali yaitu ringworm. Laporan mengenai ringworm pada sapi telah banyak di berbagai negara karena dalam usaha peternakan dapat menyebabkan kerugian ekonomi yang cukup tinggi yang disebabkan oleh kerusakan kulit serta penurunan produksi susu dan daging. Selain itu, ringworm dapat menular dari hewan ke manusia (zoonosis) (Shams-Ghahfarokhi et al., 2009). Sapi yang terinfeksi ringworm menampakkan gejala klinis berupa lesi berwarna putih keabuan berbentuk bulat dengan berbagai ukuran disertai adanya krusta, sisik, hiperkeratosis, dan alopesia (Sharma et al., 2010).

Sesungguhnya ringworm dapat sembuh sendiri, namun umumnya membutuhkan waktu yang cukup lama. Hal tersebut tergantung pada tingkat keparahan infeksia. Hewan yang terinfeksi ringworm perlu diberikan terapi karena penyakit ini mudah menyebar dan bersifat zoonosis (Bond, 2010). Efektivitas terapi ringworm, salah satunya tergantung pada spesies dermatofita penyebab ringworm. Terdapat dua jenis invasi jamur dermatofita, yakni ectothrix dan endothrix. Tipe ectothrix dicirikan dengan pembentukan arthrokonidia pada permukaan batang rambut. Tipe endothrix dicirikan dengan pembentukan arthrokonidia di dalam batang rambut (Ellis, 2015). Apabila hewan terinfeksi spesies dermatofita tipe endothrix, maka dibutuhkan terapi yang bersifat sistemik, namun apabila hewan terinfeksi spesies tipe ectothrix, maka pemberian terapi topikal mungkin sudah cukup. Pemberian terapi sistemik maupun terapi topikal tentunya membutuhkan biaya apalagi dengan populasi ternak yang besar karena perawatan untuk penyakit ini membutuhkan waktu yang cukup lama.
Laporan mengenai spesies yang menginfeksi sapi sudah cukup banyak, beberapa di antaranya oleh Al-Ani et al. (2002), ShamsGhahfarokhi et al. (2009), Sharma et al. (2010), Swai dan Sanka (2012), El-Ashmawy et al. (2015), dan Pal (2017), namun laporan mengenai spesies yang menginfeksi sapi bali di Indonesia khususnya di Bali belum tersedia. Berdasarkan hal tersebut maka diperlukan suatu penelitian untuk mengetahui spesies dermatofita yang menginfeksi sapi bali. Hasil penelitian ini diharapkan bermanfaat untuk menentukan jenis terapi yang tepat dan efektif pada sapi bali yang terinfeksi ringworm.

\section{METODE PENELITIAN}

Sampel yang digunakan dalam penelitian ini adalah kerokan kulit dan rambut sapi bali yang diduga terinfeksi ringworm. Sampel diambil menggunakan teknik superficial skin scraping dan trichogram (hair pluck). Sampel diambil di Sentra Pembibitan Sapi Bali, Sobangan, Mengwi, Badung, Bali dan peternakan tradisional di Desa Sari Mekar, Buleleng, Bali. Sapi didiagnosis terinfeksi ringworm apabila menunjukkan gejala klinis berupa lesi berwarna putih keabuan atau kehitaman berbentuk bulat disertai adanya krusta, sisik, hiperkeratosis, dan alopesia dengan berbagai ukuran. Selanjutnya dilakukan pemeriksaan mikroskopis terhadap sampel kerokan kulit dan rambut. Dalam penelitian ini ditemukan delapan ekor sapi bali yang didugauat menderita ringworm.

Lesi kulit dibersihkan menggunakan kapas yang dibasahi alkohol 70\%. Selanjutnya sampel kerokan kulit diambil menggunakan teknik superficial skin scraping dengan cara dilakukan pengerokan kulit pada bagian pinggir lesi dengan menggunakan pisau bedah (blade) namun kerokan yang dibuat tidak terlalu dalam (hanya sebatas lapisan epidermis). Sampel rambut diambil menggunakan teknik trichogram (hair pluck) dengan cara beberapa helai rambut di daerah pinggir lesi dicabut menggunakan pinset atau needle holder. Daerah lesi tempat sampel diambil ditetesi betadine untuk mencegah masuknya infeksi oleh agen penyakit lain. Sampel kerokan kulit dan rambut sapi disimpan dalam plastik sampel.

\section{Pemeriksaan Mikroskopis Langsung}

Sampel diletakkan di atas gelas objek, 
ditetesi KOH 10\% (Biomedika, Surabaya), ditutup dengan gelas penutup, dan didiamkan selama 10-15 menit dalam suhu ruang (Ellis, 2015). Sampel kemudian diperiksa menggunakan mikroskop cahaya dengan perbesaran 100 dan 400 kali untuk melihat adanya elemen fungi seperti arthrospora atau hifa.

\section{Isolasi Fungi Dermatofita}

Ose terlebih dahulu dicelupkan ke dalam alkohol dan dibakar pada api Bunsen, kemudian didiamkan sesaat. Ose selanjutnya digunakan untuk mengambil kerokan kulit dan rambut dan diusapkan pada media Sabauroud's Dextrose Agar (SDA) (Oxoid, United Kingdom). Media SDA diinkubasikan pada suhu kamar $\left(25-30^{\circ} \mathrm{C}\right)$ selama 1-3 minggu (Ellis, 2015).

\section{Identifikasi Spesies Dermatofita}

Identifikasi terhadap pertumbuhan fungi dermatofita dilakukan secara makroskopis dan mikroskopis. Pengamatan secara makroskopis dilakukan terhadap lama waktu terjadinya pertumbuhan, morfologi koloni dan warna, bentuk, dan permukaan bawah koloni. Pemeriksaan mikroskopis dilakukan terhadap media SDA yang teramati positif (tumbuh koloni fungi) menggunakan Lactophenol Cotton Blue (LPCB). Ose dicelupkan di dalam alkohol dan dibakar pada api bunsen kemudian didiamkan sesaat. Selanjutnya ose digoreskan pada koloni fungi dermatofita yang tumbuh pada media SDA kemudian diusapkan pada gelas objek yang sebelumnya telah ditetesi LPCB dan ditutup dengan gelas penutup, kemudian diperiksa menggunakan mikroskop cahaya terhadap adanya hifa, makrokonidia, dan mikrokonidia (Nasimuddin et al., 2014; El-ashmawy et al., 2015). Data yang diperoleh dianalisis secara deskriptif.

\section{HASIL DAN PEMBAHASAN}

Pengamatan yang dilakukan pada sapi bali di Sentra Pembibitan Sapi Bali Sobangan, Mengwi, Badung dan di Desa Sari Mekar, Buleleng didapatkan hasil delapan ekor sapi bali yang diduga kuat terinfeksi ringworm. Sampel kerokan kulit dan rambut dari delapan sapi bali tersebut diambil kemudian dilakukan pemeriksaan mikroskopis langsung, setelah diberi perlakuan larutan $\mathrm{KOH}$ 10\%. Hasilnya ditemukan bentukan berupa bulatan-bulatan bening yang bergerombol atau tersusun seperti rantai pada delapan sampel kerokan kulit dan rambut sapi bali tersebut (Gambar 1). Bentukan tersebut diduga sebagai elemen fungi (arthrospora). Untuk memastikan bahwa bentukan tersebut adalah fungi dermatofita maka sampel kerokan kulit dan rambut sapi bali tersebut kemudian ditanam pada media SDA. Hasilnya pada media SDA setelah diinkubasi selama tujuh hari tumbuh koloni fungi dengan tekstur seperti beludru atau kapas dan halus berwarna putih pada bagian atas koloni, sedangkan pada bagian bawah koloni tampak berwarna kuning cerah dengan ukuran yang tidak terlalu besar namun ukurannya semakin bertambah seiring bertambahnya lama waktu inkubasi (Gambar 2). Selain koloni yang diduga koloni fungi dermatofita, pada media SDA juga tumbuh koloni fungi yang lain yang diduga adalah fungi kontaminan. Untuk memurnikan koloni fungi dermatofita maka dilakukan rekultur koloni fungi dermatofita. Setelah dilakukan beberapa kali rekultur ternyata masih saja terdapat sedikit kontaminasi pada media sehingga tidak didapatkan gambar koloni fungi dermatofita yang benar-benar bersih dari kontaminan. Selanjutnya dilakukan pemeriksaan secara mikroskopis menggunakan LPCB dan hasilnya ditemukan makrokonidia berbentuk boat shape berdinding tipis dengan 4-6 sel di dalamnya. Mikrokonidia sangat jarang ditemukan. Hifanya sangat banyak dan panjang. Dermatofita tersebut diidentifikasi sebagai Microsporum gypseum (Gambar 3a). Selain itu juga ditemukan makrokonidia berbentuk ovoid berdinding tipis dengan 1-3 sel di dalamnya. Dermatofita tersebut diidentifikasi sebagai $M$. nanum (Gambar 3b) (Hardy Diagnostics, 2016).

Jamur dermatofita dikelompokkan menjadi tiga grup berdasarkan tempat hidup alaminya, yaitu zoofilik, geofilik, dan anthropofilik (Dehghan et al., 2009). Dermatofita zoofilik terutama bersifat parasit pada hewan, namun juga mampu menyebabkan infeksi pada manusia. Beberapa di antaranya, yaitu $M$. canis, $T$. verrucosum, dan T. mentagrophytes. Dermatofita geofilik hidup di tanah sebagai saprofit. Contohnya adalah $M$. gypseum dan $M$. nanum (Mahmoudabadi, 2010). Manusia merupakan hospes utama dermatofita anthropofilik, namun kemungkinan dapat juga menyebabkan infeksi pada hewan. Contohnya adalah $T$. rubrum dan Epidermophyton floccosum (Lakshmipathy dan Kannabiran, 2010). 


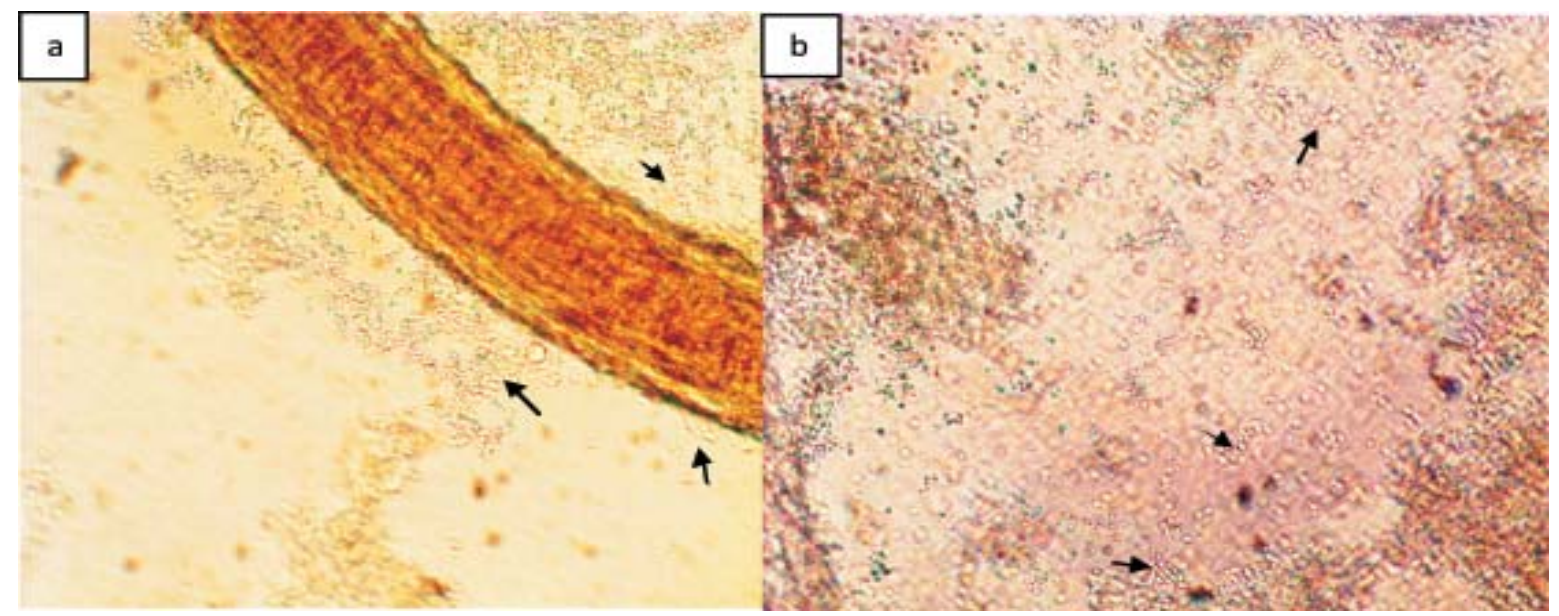

Gambar 1. (a) Hasil pemeriksaan mikroskopis rambut ditemukan adanya arthrospora (panah hitam), (b) Hasil pemeriksaan mikroskopis kerokan kulit ditemukan adanya arthrospora,b (panah hitam)

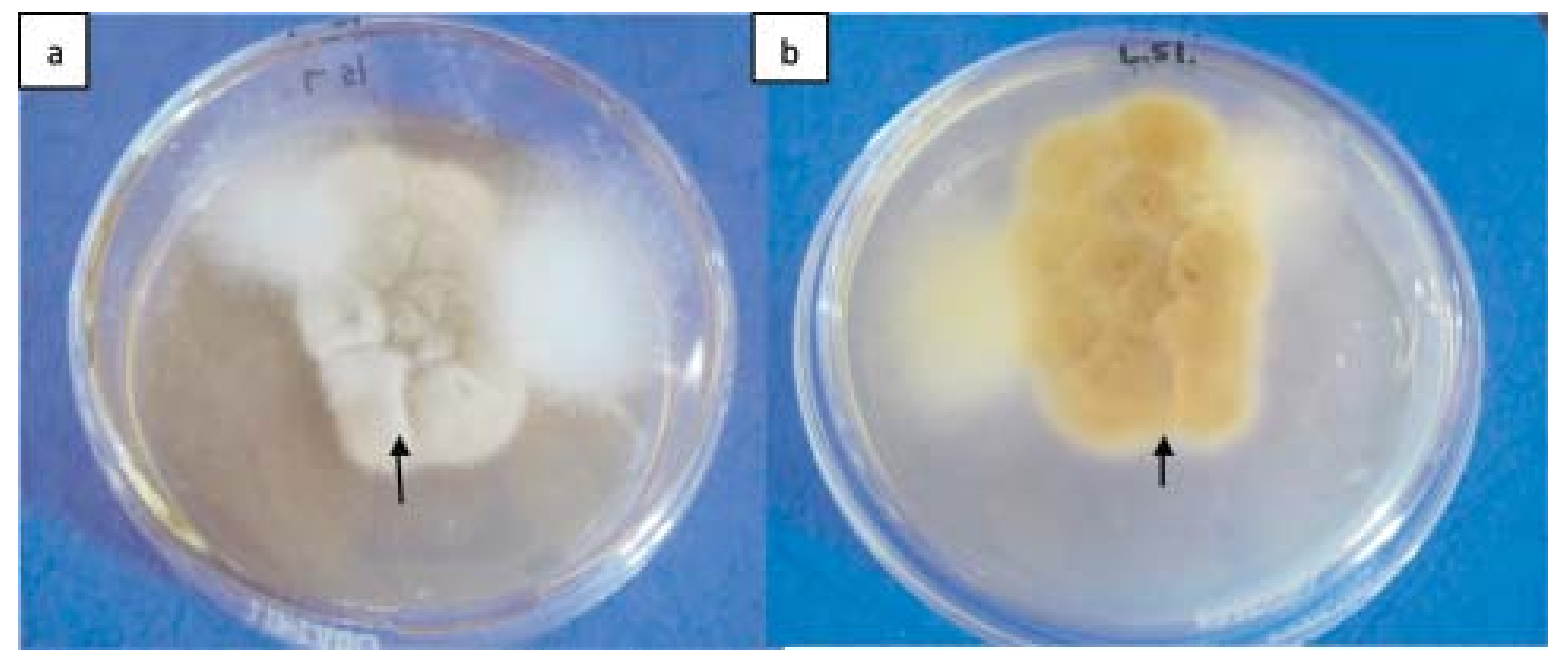

Gambar 2. (a) Hasil kultur pada media SDA, koloni fungi dermatofita tampak depan (panah hitam), (b) Hasil kultur pada media SDA, koloni fungi dermatofita tampak belakang (panah hitam)

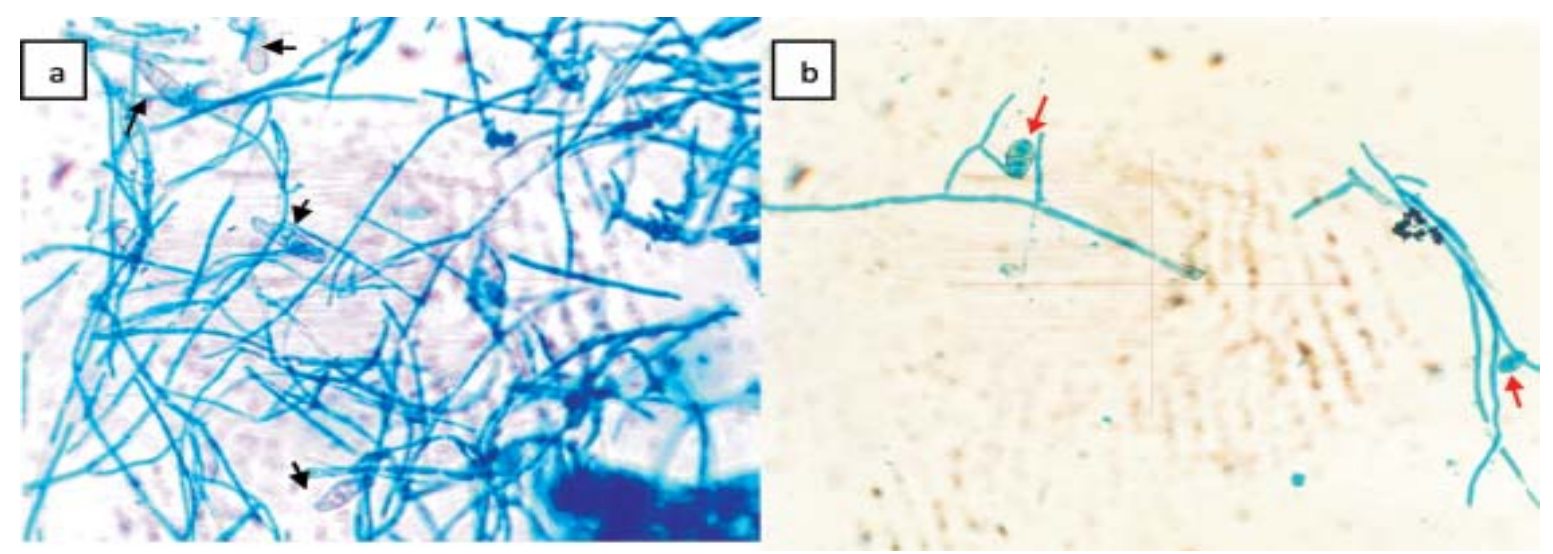

Gambar 3. (a) Hasil pewarnaan koloni menggunakan lactophenol cotton blue (LPCB), ditemukan Microsporum gypseum (panah hitam), (b) Hasil pewarnaan koloni menggunakan LPCB, ditemukan Microsporum nanum (panah merah) 
Merchant (2013) menyatakan bahwa $T$. verrucosum merupakan fungi dermatofita yang paling umum menyebabkan ringworm pada sapi. Namun T. mentagrophytes, T. equinum, $M$. gypseum, $M$. nanum, $M$. canis, dan spesies dermatofita lain juga telah berhasil diisolasi dari sapi. Di Iran Timur, dari total isolat 99\% fungi dermatofita teridentifikasi adalah $T$. verrucosum dan sisanya $1 \%$ adalah $T$. mentagrophytes (Shams-Ghahfarokhi et al., 2009). Di Yordania, fungi dermatofita yang berhasil diisolasi yaitu $T$. verrucosum $(47,88 \%) ; T$. mentagrophytes (12,68\%); T. schoenleinii (4,22\%); T. terrester, M. audouinii, $M$. nanum, $M$. distortum masing-masing $2,82 \%$; $T$. violaceum $(1,41 \%)$, dan sisanya sebesar $22,53 \%$ bukan merupakan fungi dermatofita (Al-Ani et al., 2002).

Hasil penelitian ini sedikit berbeda dengan hasil penelitian tersebut. Pada penelitian ini, dermatofita yang berhasil diisolasi dari sapi bali yang dicurigai ringworm adalah $M$. gypseum dan $M$. nanum. Fungi $T$. verrucosum yang merupakan dermatofita yang paling umum menginfeksi sapi tidak ditemukan. M. gypseum merupakan spesies fungi dermatofita yang termasuk dalam kelompok geofilik dan dapat ditemukan pada tanah di seluruh dunia (Lakshmipathy dan Kannabiran, 2010). Sifat invasi/infeksi $M$. gypseum adalah ectothrix. $M$. nanum termasuk dalam kelompok geofilik dan zoofilik. Sifat invasi/infeksi $M$. nanum adalah ectothrix (Ellis, 2015).

Tipe invasi/infeksi ectothrix dicirikan dengan pembentukan arthrokonidial arthrospora pada permukaan atau superfisial batang rambut (Ellis, 2015). Dermatofita tipe invasi ectothrix tidak dapat menginvasi masuk ke dalam batang rambut. Oleh sebab itu terapi topikal dipandang cukup untuk mengatasi infeksi $M$. gypseum dan $M$. nanum, selama lesi yang ditimbulkan masih bersifat terbatas. Sapi yang terinfeksi ringworm yang diambil sampelnya dalam penelitian ini lesinya masih bersifat terbatas. Bila lesi yang ditimbulkan sudah bersifat meluas maka juga dibutuhkan kombinasi dengan terapi yang bersifat sistemik.

Ringworm pada hewan sesungguhnya dapat sembuh secara spontan dalam waktu satu sampai beberapa bulan. Namun tetap disarankan untuk melakukan terapi pada penyakit ini. Tujuan dari pemberian terapi fungi adalah memaksimalkan kemampuan pasien mengatasi infeksi dermatofita; untuk mengurangi penyebaran infeksi ke lingkungan, hewan lain, dan manusia; dan untuk mempercepat kesembuhan infeksi. Beberapa terapi topikal yang dilaporkan baik penggunaannya guna menangani ringworm pada sapi yaitu lime sulfur 4\%, sodium hypochlorite 0,5\% (1:10), chlorhexidine $0,5 \%, 1 \%$ povidoneiodine $1 \%$, natamycin, dan enilconazole. Lesi lokal atau individual dapat diberikan lotion miconazole atau clotrimazole (Bond, 2010).

\section{SIMPULAN}

Fungi dermatofita yang berhasil diisolasi dan diidentifikasi dari sapi bali adalah $M$. gypseum sebesar $75 \%$ (6/8) dan $M$. nanum sebesar $25 \%(2 / 8)$.

\section{SARAN}

Perlu dilakukannya sosialisasi mengenai penyakit ringworm ini kepada para peternak sehingga dapat dilakukan terapi yang tepat dan dapat mencegah penularan serta penyebarannya.

\section{UCAPAN TERIMA KASIH}

Penulis mengucapkan terima kasih kepada Lembaga Penelitian dan Pengabdian Kepada Masyarakat Universitas Udayana yang telah memberikan dana (hibah penelitian 2014) Skim Hibah Unggulan Program Studi dengan nomor kontrak 246-181/UN14.2/PNL.01.03.00/2015, untuk dapat dilaksanakannya penelitian ini.

\section{DAFTAR PUSTAKA}

Al-Ani FK, Younes FA, Al-Rawashdeh. 2002. Ringworm infection in cattle and horse in Jordan. Acta Vet Brno 71: 55-60.

Aneja KR, Joshi R, Sharma C, Surain P, Aneja A. 2012. Biodiversity of dermatophytes: an overview. Rev Plant Pathol 5: 299-314.

Bond R. 2010. Superficial veterinary mycoses. Clinics in Dermatology 28: 226-236.

Dehghan M, Haiian S, Alborzi N, Borgheyee A, Noohi AH. 2009. Clinico - mycological profiles of dermatophytosis in Gorgan, North of Iran. J Dermatol 12(1): 13-15. 
El-Ashmawy WR, El Hafez EA, El Saeed HA. 2015. Clinical study on dermatophytosis in calves with in vitro evaluation of antifungal activity of bergamot oil. Advances in Animal and Veterinary Sciences 3(1): 34-39.

Ellis D. 2015. Dermatophytosis. https:// mycology.adelaide.edu.au/ Diakses pada tanggal 9 Februari 2015.

Hardy Diagnostics. Dermatophyte Identification Chart. https://catalog.hardydiagnostics. com/. Diakses pada tanggal 10 Desember 2017.

Lakshmipathy DT, Kannabiran K. 2010. Review on dermatomycosis: pathogenesis and treatment. Natural Science 2(7): 726-731.

Mahmoudabadi A. 2010. Cutaneous mycosis in a rural area of Ahvaz, Iran. Jundishapur J Microbiol 3(3): 133-135.

Nasimuddin S, Appalaraju B, Surendran P, Srinivas CR. 2014. Isolation, identification and comparatative analysis of SDA and DTM for dermatophytes from clinical samples in a tertiary care hospital. IOSR Journal of Dental and Medical Sciences 13(11): 68-73.
Pal M. 2017. Dermatophytosis in an adult cattle due to Trichophyton verrucosum. Animal Husbandry, Dairy and Veterinary Science 1(1): 1-3.

Shams-Ghahfarokhi M, Mosleh-Tehrani F, Ranjbar-Bahadori S, Razzaghi-Abyaneh M. 2009. An epidemiological survey on cattle ringworm in major dairy farms of Masshad City, Eastern Iran. Iranian Journal of Microbiology 1(3): 31-36.

Sharma DK, Joshi G, Singathia R, Lakhotia LR. 2010. Fungal infections in cattle in a Gaushala At Jaipur. Haryana Veterinarian 49: 62-63.

Swai dan Sanka PN. 2012. Bovine dermatophytosis caused by Trychophyton verrucosum: a case report. Vet World 5(5): 297-300.

Vermout S, Tabart J, Baldo A, Mathy A, Losson B, Mignon B. 2008. Pathogenesis of dermatophytosis. Mycopathologia 166: 267275 . 